
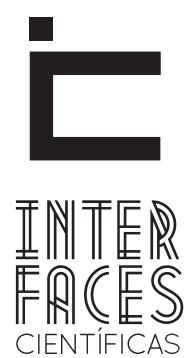

EDUCAÇÃO

\title{
SALTO PARA O FUTURO: UMA EXPERIÊNCIA DE POLÍTICAS PÚBLICAS DO USO DAS NOVAS TECNOLOGIAS DA INFORMAÇÃO E COMUNICAÇÃO PARA A FORMAÇ̃̃O CONTINUADA DOCENTE
}

Andréa Karla Ferreira Nunes ${ }^{1}$ Alexandre Meneses Chagas $^{3}$

\section{RESUMO}

Este artigo traz a discussão sobre a importância da formação continuada docente através do uso das novas tecnologias da informação e comunicação. Para tanto, apresenta na introdução as mudanças ocorridas na sociedade e na educação com o avanço tecnológico. No desenvolvimento, faz referência ao novo perfil docente exigido, o que endossa a relevância da formação continuada dos professores, enfatiza a significância dos programas de políticas públicas e analisa as contribuições do Programa Salto para o Futuro no Estado de Sergipe.

\section{PALAVRAS-CHAVE}

Educação. Formação Continuada Docente. Políticas Públicas. Tecnologias da Educação e Comunicação. Programa Salto Para o Futuro.
Kalyne Andrade Ribeiro ${ }^{2}$

\section{ABSTRACT}

This paper will discuss the importance of teachers continued formation through the use of new information and communication technologies. Therefore, the introduction presents the changes in society and education with technological advancement. In the development, it will refer to the new profile required for teacher's nowdays, which endorses the importance of teachers continuous training, emphasizes the significance of public policy programs and analyzes the contributions of the Programa Salto para o Futuro in the State of Sergipe.

\section{KEYWORDS}

Education. Teacher Training. Public Policy. Information Technology and Communication. Programa Salto para o Futuro. 


\section{RESUMEN}

En este artículo presenta una discusión sobre la importancia de continuar la formación del profesorado a través de la adhesión de nuevas tecnologías de la información y la comunicación. Y para ello, expone en la introducción, los cambios ocurridos en la sociedad y en la educación con el avance tecnológico. En el desarrollo, hace referencia al nuevo perfil docente requerido, que avala la importancia de la formación continua de los docentes, haciendo hin-

\section{INTRODUÇÃO}

As transformações econômicas, políticas, culturais e sociais ocorridas no País têm levado a análises importantes acerca do papel da escola e dos professores. É sabido que não é apenas na escola que os conhecimentos são adquiridos, todavia, ela ainda se constitui como instituição que possui considerável relevância para a democratização da sociedade.

\begin{abstract}
Num mundo globalizado, transnacional, nossos alunos precisam estar preparados para uma leitura crítica das transformações que ocorrem em escala mundial. Num mundo de intensas transformações científicas e tecnológicas, precisam de uma formação geral sólida, capaz de ajudá-los na sua capacidade de pensar cientificamente os problemas humanos (LIBÂNEO, 2012, p.8).
\end{abstract}

A escola deve ser um lugar que possibilite a formação de sujeitos pensantes, capazes de influenciarem a sociedade em que vivem de forma plena, consciente e efetiva, pois como nos diz Mercado (2002) "ela não é apenas um espaço físico. É acima de tudo um modo de ser e ver. Ela se define pelas relações sociais que desenvolve". Nela a aprendizagem deve acontecer ultrapassando os conteúdos dispostos no currículo, extinguindo-se, assim, os espaços existentes entre os alunos e a ciência, e a tecnologia, e a pesquisa, e o marasmo intelectual e cultural. 0 papel da escola é indis- capié en la importancia de los programas de política pública y analizando las aportaciones del Programa Salto para o Futuro en el estado de Sergipe.

\section{PALABRAS CLAVE}

La educación. Maestro de Educación Continua. Políticas Públicas. Tecnología para la Educación y la Comunicación. Programa Salto para o Futuro.

pensável na preparação dos indivíduos para o enfrentamento das exigências do mundo contemporâneo.

A escola da Sociedade da Informação deverá transformar o exercício único de transmitir/assimilar conhecimentos e repetir atitudes/habilidades ampliando assim, seu universo cognitivo com o ato de conhecer/ produzir/comunicar saberes e conhecimentos (LIMA, 2002, p. 4).

Porém, é importante ressaltar que para que a escola desempenhe com eficiência o seu papel e alcance seus objetivos é primordial que ela também esteja disposta a mudanças e transformações, pois, como nos diz Guerra (2001, p. 60) “uma escola que se fecha não está em condições de aprender, nem de se desenvolver”.

Para isso, ela deve analisar sua proposta pedagógica, o material didático, a metodologia de ensino utilizada e principalmente, seu corpo docente. 0 destaque dado ao corpo docente tem razões óbvias: os professores são os mediadores do conhecimento e sua formação é imprescindível para a oferta de uma educação de boa qualidade.

Mas, diante de uma sociedade tecnológica, muitos questionam se há espaço para a escola e ainda mais, 
se o professor ainda terá alguma função nesse contexto. E a resposta é sim. Como nos afirma Libâneo,

Não só o professor tem o seu lugar, como sua presença torna-se indispensável para a criação das condições cognitivas e afetivas que ajudarão o aluno a atribuir significados às mensagens e informações recebidas das mídias, das multimídias e formas variadas de intervenção educativa urbana (LIBÂNEO, 2012, pp. 27-28).

No entanto, os professores precisam rever as suas práticas e criarem arranjos didáticos na tentativa de atenderem as diferentes necessidades dos seus alunos. Um perfil diferenciado é exigido dos docentes. Eles precisam estar dispostos a aprender, o que aniquila o paradigma de que o professor é o detentor do conhecimento e possibilita a construção de uma cultura geral significativa através da troca de experiências com os alunos. Precisam ainda ter competências e habilidades para lidarem com os desafios surgidos no ambiente escolar, e muitas vezes fora dele, além de serem articuladores das informações expostas nas mídias e a aulas ministradas.

\section{AVANÇO TECNOLÓGICO E FORMAÇÃO CONTI- NUADA DOS PROFESSORES}

Discute-se muito sobre os avanços tecnológicos e as consequências desses avanços na educação. Mas é perceptível que as discussões tendem a priorizar o uso dos recursos tecnológicos para a formação discente. Elaboram-se projetos de implantação de laboratórios de informática, aquisição de acervo digitação, utilização de softwares educativos, mas tudo isso com intuito de viabilizar o acesso dos alunos às tecnologias digitais. Contudo, é importante analisar também esse processo por outro plano de visão, ou seja, como esses recursos podem contribuir para a formação continuada docente, possibilitando uma mudança de comportamento, gerando assim, ações significativas para o desenvolvimento de uma práxis eficiente.
Grandes são os desafios impostos aos docentes. E para que eles sejam bem sucedidos é necessário que a formação seja um processo contínuo, apenas a formação inicial não é suficiente. Os professores precisam constantemente analisar e discutir as suas práticas, compartilhar experiências e criar novas estratégias de atuação. Para tanto, várias ferramentas podem ser utilizadas, como por exemplo, as novas tecnologias da informação e comunicação.

Pode parecer difícil, e ainda pode sofrer resistência ou descrédito, mediante a diversidade de usos que muitas vezes são improdutivos, mas as tecnologias digitais, como são chamadas atualmente as TICs, podem ser utilizadas para a formação continuada dos professores, exemplo disso, é o programa Salto para o Futuro. E o presente artigo tem por objetivo apresentar os resultados, ainda parciais, da importância desse programa, no Estado de Sergipe, para a formação continuada docente.

A sociedade vem modificando-se ao longo do tempo e essas mudanças influenciam nas mais diversas áreas, inclusive na educação. Exigem-se outros padrões nos modos de ensinar e aprender. 0 professor como um dos principais atores do cenário educativo e tendo por função contribuir para a mediação do conhecimento, é alvejado constantemente por essas exigências. E não é aceitável que ele fique as margens desse processo. Isso porque, "a prática do professor não permite soluções e compreensões superficiais" (VIEIRA, 2003, p. 65).

Já faz algum tempo que não há mais como justificar a atuação docente como vocação ou dom, base- 
ada apenas em qualidades morais. É necessário um repertório de competências específicas e de saberes próprios para o sucesso educativo. Mas como nos diz Branco (2003, p. 424) “[...] ninguém dá o que não tem [...]”. É perceptível que os níveis de formação docente têm deixado a desejar. Seja porque essa formação é ofertada por instituições sem idoneidade, seja pelo modelo de currículo adotado ou até mesmo pela desvalorização profissional que termina por não primar pela boa qualidade. Sendo assim, a formação continuada passa a ter um papel ainda mais relevante. Muito mais quando se é sabido que a sua qualificação eleva os níveis de qualidade da educação.

Mas é comum os docentes enfrentarem sozinhos as dificuldades que permeiam a sua prática. E ainda mais frequente é deparar-se com a afirmativa que as mudanças necessárias dependem apenas do querer e da disposição do professor, o que não é verdade. É preciso dar ao docente condições para se capacitar tornando menor o distanciamento entre sua formação e as necessidades impostas pela sociedade. E o uso das tecnologias da informação e da comunicação é extremamente importante tendo em vista sua abrangência, o que facilita a disseminação do conhecimento.

\footnotetext{
É importante ressaltar que,
}

\section{PROGRAMAS DE POLITICAS PÚBLICAS PARA FORMAČ̃O CONTINUADA DOS PROFESSORES: 0 MODELO DO PROGRAMA SALTO PARA O FUTURO}

Com raízes na Grécia Antiga, a palavra "política”, que em grego é politika, origina-se da palavra polis, ou seja, cidade; comunidade organizada formada por cidadãos. E ela foi criada pelos homens para que eles pudessem expressar suas diferenças e conflitos discutindo entre si a melhor maneira de organizar a sociedade. Muitos usos existem para a palavra política,
Quando falamos de tecnologias da informação e da comunicação não nos referimos apenas à internet, mas ao conjunto de tecnologias microeletrônicas, informáticas e de telecomunicações que permitem a aquisição, produção, armazenamento, processamento e transmissão de dados na forma de imagem, vídeo, texto ou áudio (TEDESCO, 2004, p. 96).

Ferramentas como o rádio e a televisão podem ser utilizadas para a aquisição de conhecimentos e o aperfeiçoamento profissional do docente. Isso se justifica pelo fato de que a aprendizagem ocorre em diferentes espaços, de formas diversificadas e por meios de vários agentes. 0 que diferencia é a intencionalidade, ou seja, os objetivos propostos na utilização das ferramentas é quem darão o norte, que propiciarão a aquisição de conhecimento, as oportunidades de discussão, o compartilhamento de experiências, a mudança de atitude e consequentemente, as melhorias no ensino.

Todavia, é importante ressaltar que não é suficiente apenas pensar na formação e na capacitação docente, mas é também preciso cobrar políticas públicas educacionais que possibilitem melhorias e transformações efetivas no sistema escolar. mas em âmbito geral ela diz respeito a tudo quanto envolva relações de poder ou organização e administração de grupos, e isso é independente de quem a pratica, quer sejam políticos ou a própria sociedade.

Política é a gerência dos costumes e leis. É a gerência da organização da defesa e da guerra, da ad- 
ministração dos serviços públicos e das atividades econômicas do Estado. Estado esse, gerido pelo Governo, que, segundo o Dicionário Michaelis (2010), é o conjunto de órgãos responsáveis pela realização da administração pública, através de poderes delegados pelo povo. E para atender as necessidades da sociedade, de maneira justa e igualitária, tornando assim, eficazes as decisões do Governo, estão as Políticas Públicas.

Segundo Guareschi (2004), Políticas Públicas é o conjunto de ações coletivas voltadas para a garantia dos direitos sociais, configurando um compromisso público que visa dar conta de determinada demanda, em diversas áreas. Expressa a transformação daquilo que é âmbito privado em ações coletivas no espaço público. E elas também estão presentes na educação e, destacadas nesste artigo, na formação continuada dos professores.

A formação docente continuada é direito garantido pela Lei de Diretrizes e Bases da Educação em seu Art. $63^{\circ}$ (BRASIL, 1996). Mas houve um longo caminho a ser percorrido até essa conquista. Muitas discussões, embates e reivindicações foram necessários ao longo da história, tendo sua importância acentuada com a inserção das Tecnologias da Informação e Comunicação.

E o Governo, através do Ministério da Educação, na tentativa de cumprir o seu papel de gerenciador das coisas públicas e de viabilizador de uma educação de qualidade, criou diversos programas de qualificação docente. Projetos como Proninfe, TV Escola, Prolnfo Integrado, Pró-Letramento e muitos outros. Todos esses extremamente importantes, mas como nosso objeto de estudo, iremos ressaltar o Salto para o Futuro.

O Programa Salto para o Futuro é um programa direcionado à formação continuada de professores e gestores da Educação Básica, tendo por idealizadores e motivadores o Ministério da Educação e a Fundação Roquette Pinto. Sua primeira edição foi transmitida pela TVE Brasil no dia $1^{\circ}$ de agosto de 1991, em uma experiência inicial de Educação a Distância, e ainda era denominado Jornal da Educação - Edição do Professor. No ano de 1992 o programa passou a se chamar Um Salto para o Futuro e em 1995 houve mais uma vez a mudança em sua denominação, passando a Salto para o Futuro. Nesse mesmo ano, o programa passou a fazer parte da programação da TV Escola, canal do Ministério da Educação.

O programa tem por objetivo debater propostas pedagógicas que contribuam para a reflexão das práticas educativas realizadas em sala de aula, trazendo assim, novas possibilidades de atuação docente. Os diálogos aconteciam de forma direta entre os professores e especialistas da área educacional e até o ano de 2008 o programa era apresentado diariamente e ao vivo, viabilizando a participação dos professores através de telessalas, com a mediação de um orientador de aprendizagem.

Além da sua programação televisiva diária, outros recursos como caixa postal, fax e telefone eram utilizados. E posteriormente, também a internet, onde foi criada no ano de 2000 a página do Salto para o Futuro. Nela, a participação dos professores afirmou ainda mais o caráter dialógico do programa.

E diante das mudanças ocorridas na sociedade 0 programa também se modificou, assumindo em 2009 um novo formato, atendendo aos novos conceitos e possibilidades geradas pelas tecnologias digitais. Em 2013 percebe-se a necessidade de outras mudanças e passa a ser apresentado em dois programas semanais que são: Salto revista, com apresentação as segundas-feiras; e Salto debate as quartas-feiras, ambos às $17 \mathrm{~h}$. 


\section{SALTO PARA O FUTURO E AS EXPERIÊNCIAS EM SERGIPE}

Como ora dito, o Programa Salto para o Futuro surgiu no ano de 1991 e, a princípio, com recepção em apenas seis Estados do País. Em 1992, a sua abrangência foi nacional, alcançando então o Estado de Sergipe. Neste Estado, o programa teve uma coordenação que era subordinada ao Departamento de Educação e as atividades eram realizadas no Centro de Treinamento e Aperfeiçoamento Jackson de Figueiredo, localizado na capital. Este espaço era um teleposto e nele havia as televisões e os vídeos. Os telepostos eram estruturas organizadas que recebiam o sinal da transmissão para desenvolver o projeto junto aos professores.

Para a execução dos objetivos propostos pelo programa houve a escolha da Equipe Coordenadora e dos Orientadores de Aprendizagem, que conduziriam os trabalhos da sala de aula. A seleção dos orientadores de aprendizagem atendeu aos critérios dispostos em documento da Fundação Roquette Pinto, cujos determinantes foram experiências no trabalho com professores em regência de classe das séries iniciais.

O programa passou então a se desenvolver e foi sendo aceito pelos professores, técnicos e diretores das escolas. A partir daí sua expansão foi inevitável. Parcerias entre as prefeituras municipais e a Secretaria da Educação foram feitas a fim de viabilizar o funcionamento dos telepostos existentes nessas cidades. Mas não havia apenas a preocupação com os espaços físicos. Havia também o cuidado com o cumprimento dos propósitos dispostos no programa, pois, a reflexão da prática pedagógica era o objetivo principal. Para isso, muitos encontros pedagógicos foram realizados, com a participação da equipe central, dos orientadores de aprendizagem, de diretores e técnicos visando à troca de experiências, as discussões sobre as dificuldades enfrentadas e o aprofundamento teórico.
Nos documentos pesquisados no acervo da Divisão de Tecnologia de Ensino foram encontradas programações de encontros, que ocorreram no ano de 1994. O I Encontro Pedagógico aconteceu no dia 23 de março e tinha como objetivo capacitar os orientadores de aprendizagem apresentando conteúdos que embasariam as atividades a serem desenvolvidas nas séries determinadas. Além desse, houve o II Encontro Pedagógico, que foi realizado em dois momentos, em 9 e 10 de agosto e 23 e 24 de agosto de 1994. Nesse encontro, três objetivos foram priorizados: aprofundar os conhecimentos teórico-metodológicos do ensino de educação a distância; propiciar meios de atualização e aperfeiçoamento dos orientadores de aprendizagem, superiores e monitores, para o desenvolvimento das atividades no ensino de educação a distância, e difundir experiências de aprendizagem, desenvolvidas pelos orientadores de aprendizagem nas Diretorias Regionais de Educação e em telessalas.

Muitas atividades eram desenvolvidas frequentemente nos telepostos, sempre embasadas pelos conteúdos abordados pelos textos de apoio, os chamados boletins, e pela exposição dos especialistas. Exemplos dessas atividades foram: a formação de grupos para confecção de material didático-pedagógico como painéis, maquetes, bingos, etc.; as discussões sistemáticas acerca dos temas trabalhados; a produção de textos individuais e coletivos sobre os temas abordados; palestras ministradas por especialistas; dramatização; construção coletiva de um jornal; atividades envolvendo musicalização, dança e expressão corporal; e exposição oral.

Além disso, estudos eram realizados. Utilizavam-se textos e livros da bibliografia indicada, como também fitas de vídeo, fax, telefone e mais recentemente, a internet. Tudo isso tendo por foco a reflexão sobre a importância da inovação na prática pedagógica, sem, 
no entanto, esquecer-se da aprendizagem e da vivência do aluno. A oportunização da formação contínua também alcançou os professores da Educação Especial e da Educação Física. Eles foram orientados por especialistas que contribuíram de forma significativa para vencer as dificuldades encontradas em seu cotidiano escolar. No caso específico da Educação Física, foram realizadas demonstrações práticas de jogos, brincadeiras e recreações diversas.

Todas as atividades desenvolvidas eram acompanhadas e seus resultados analisados. 0 crescimento da participação dos professores elevava o nível de qualidade do programa, isso surtia efeitos positivos. As atividades realizadas comprovavam o envolvimento dos docentes, tanto nas discussões quanto na aplicação em sala de aula. E assim o Programa foi adquirindo credibilidade. Tornou-se notória a contribuição do programa para a transformação da postura docente. Sua proposta pedagógica apresentava um programa curricular avançado, integrando as diversas áreas do conhecimento e despertando no docente uma visão mais clara e ampla dos problemas. Visando cumprir os seus objetivos, o programa atuou nesse formato durante cinco anos.

Em 1996, por inciativa do Governo, visando atender a implantação de uma política nacional de Educação a Distância, o programa passou por novas modificações e adaptações. Ele teve sua responsabilidade transferida para a Secretaria de Comunicação Social da Presidência da República. As justificativas apresentadas relatavam a complexidade estrutural do projeto, já que eram utilizadas várias mídias e também material impresso; as dificuldades estruturais físicas; as dimensões continentais e as especificidades de cada região; e a característica da oferta através da educação a distância. Essa última tornaria possível a continuidade do programa mesmo diante das dificuldades. Porém, algumas restrições ocorreram. O programa que antes era transmitido pela TVE do Rio de Janeiro, via satélite, em canal aberto, passou a ser transmitido em canal fechado, limitando a audiência.

\section{CONCLUSÃ̃O}

Não há como negar que o enfrentamento das exigências impostas aos docentes no mundo contemporâneo passa pela formação continuada. 0 processo de aprendizagem é constante e faz-se necessário ampliar tanto quanto possível as oportunidades de aprender. Os resultados que ainda são apresentados de forma parcial, já que a pesquisa ainda acontece, mostram o quão foi importante o Programa Salto para o Futuro no processo de construção da conscientização da relevância da formação continuada dos docentes e do uso das novas tecnologias. Ele contribuiu para a transformação da escola, para a mudança na postura do professor e, consequentemente, para a oferta de uma educação mais eficiente e eficaz.
A análise feita na documentação pesquisada fez-se perceber a criação de novas estratégias de atuação e utilização de recursos facilitadores. E o envolvimento e participação dos professores endossam as oportunidades suscitadas pelo programa. Os conhecimentos adquiridos possibilitaram qualificação. Criaram situações de reflexão e aprendizagem. Suscitaram motivação e esperança. Os docentes puderam perceber que há solução para muitos problemas e que eles não passam por isso sozinhos. As discussões geraram novas estratégias de atuação, tornando assim o ambiente escolar um local de crescimento científico, intelectual, cultural e afetivo. Claro que não estamos falando em milagre! Mas muitos comportamentos foram modificados, e novos hábitos incorporados à educação, através de 
percepções alcançadas pela análise, pelas discussões

e trocas de experiências viabilizadas pelo programa.

\section{REFERÊNCIAS}

BRANCO, Adylles Castelo. A portaria n.2253/2001 no contexto da evolução da educação a distância nas instituições de ensino superior no Brasil. In: SILVA, Marco (org.). Educação Online: teorias, práticas, legislação e formação corporativa. São Paulo: Loyola, 2003.

BRASIL. Leis de Diretrizes e Bases da educação Brasileira (LDB). Lei n. 9.394, de 20 de dezembro de 1996. Brasília, 1996.

GUARESCHI, Neuza; COMUNELLO, Luciele Nardi; NARDINI, Milena; Júlio César Hoenisch. Problematizando as práticas psicológicas no modo de entender a violência. In: Violência, gênero e políticas públicas. STREY, Marlene N; AZAMBUJA, Mariana P. Ruwer; JAEGER, Fernanda Pires (orgs.). Porto Alegre, RS: EDIPUCRS, 2004.

GUERRA, M. S. A Escola que Aprende. Porto: Edições Asa, 2001.

LIBÂNEO, José Carlos. Adeus Professor, Adeus professora?: novas exigências educacionais e profissão docente. 11. ed. São Paulo: Cortez, 2012.

LIMA, Maria de Fátima Monte. Educação, Políticas Públicas e Tecnologias da Informação e da Comunicação In: No fio da esperança: políticas públicas de educação e tecnologias de informação de comunicação. Programa de Pós - graduação em Educação da Universidade Federal da Bahia. Salvador, setembro 2002.

MERCADO, Luis Paulo Leopoldo (Org.). Novas Tecnologias na Educação: reflexões sobre a prática. Maceió: Edufal, 2002.

POLÍTICA. MICHAELIS. Moderno Dicionário da Língua Portuguesa, 2010. Disponível em: < http://michaelis. uol.com.br/moderno/portugues/index.php>. Acesso: 10 maio 2013.

SERGIPE. Governo. Relatório de Atividades do Programa Salto para o Futuro - 1992, 1993 e 1994. Sergipe: Secretaria de Estado da Educação e Desporto, 1994.

TEDESCO, Juan Carlos (org.). Educação e Novas Tecnologias: esperança ou incerteza?.Tradução de Claudia Berliner e Silvana Cobucci Leite. São Paulo: Cortez; Buenos Aires: Instituto Internacional de Planejamento de La Educacion; Brasília: UNESCO, 2004.

VIEIRA, Alexandre Thomaz; ALMEIDA, Maria Elizabeth Bianconcini de; ALONSO, Myrtes (orgs.). Gestão Educacional e Tecnologia. São Paulo: Avercamp, 2005. 
1 Doutora em Educação pela Universidade Federal de Sergipe (UFS). Professora do Programa de Pós-graduação em Educação da Universidade Tiradentes (PPED-UNIT), Presidente da Comissão Própria de Avaliação - CPA/UNIT e Gerente do Projeto Enade.Email: Andrea_Karla@ unit.br.

2 Licenciatura em Pedagogia (2006) e especialização em Tecnologias Educacionais pela Universidade Tiradentes (2007). Assessora pedagógica na Coordenação do curso de Enfermagem da Universidade Tiradentes, membro dos Grupos de Pesquisa Sociedade e Desenvolvimento Regional (GPSDR) e Sociedade, Educação, História e Memória e representante suplente da Comissão Própria de Avaliação da Universidade Tiradentes. Email: kalyne_andrade@unit.br.

Recebido em: 24 de julho de 2013 Avaliado em: 29 de julho de 2013 Aceito em: 7 de agosto de 2013
3 Mestrando em Educação na Universidade Tiradentes-UNIT, GECES Grupo de Pesquisa em Comunicação, Educação e Sociedade, e-mail: profamchagas@gmail.com 